Revista Tecné, Episteme y Didaxis: TED. Año 2014, Número Extraordinario. ISSN Impreso: 0121-3814, ISSN web: 2323-0126

Memorias, Sexto Congreso Internacional sobre Formación de Profesores de Ciencias. 08 al 10 de octubre de 2014, Bogotá

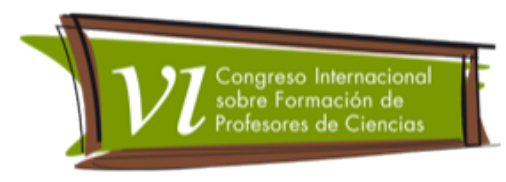

\title{
A pesquisa sobre o ensino da relatividade especial e geral: implicações para a prática docente
}

Londero Leandro', Pereira Johnny Gonçalves²

Categoria 2. Trabalho de investigação

\section{Resumo}

Em nosso estudo, investigamos as contribuições das pesquisas sobre o Ensino da Teoria da Relatividade Especial e Geral (TREG) e suas implicações para a prática docente. Para tanto, revisamos atas de 03 congressos científicos realizados no Brasil. Mapeamos 44 estudos, os quais foram categorizados de acordo com seus propósitos. Identificamos uma grande quantidade de produções, com foco na análise de conteúdos em livros, na formação de conceitos e na implementação de propostas didáticas, o que permite-nos inferir que, a procura por alternativas para que o ensino da TREG seja realmente efetivado se faz necessária e 0 aumento de investigações no ambiente escolar parece o caminho mais acertado. Há, também, uma necessidade de investirmos esforços na formação inicial dos professores, para que eles sintam-se seguros para abordar a TREG, quando estiverem em atividade docente.

\section{Palavras-chave}

Relatividade Especial e Geral, Ensino de Física, Estado do Conhecimento, Prática Pedagógica

\section{Objetivo}

Este estudo partiu da constatação da ausência, na literatura consultada, de um estudo que analise as contribuições e implicações das pesquisas sobre o ensino da TREG para a prática docente de professores de física. Perante isso, realizamos uma revisão bibliográfica, analisando aspectos quantitativos e qualitativos referentes a produção acadêmica sobre o ensino da TREG, tomando como fonte de informações as atas de congressos científicos. Buscamos sintetizar os avanços obtidos, as ideias convergentes e procuramos sinalizar perspectivas. Além disso,

\footnotetext{
1 Universidade Estadual Paulista "Júlio de Mesquista Filho" - UNESP. leandrolondero@gmail.com

2 Universidade Federal de Alfenas - UNIFAL. johnnygoncalvespereira@gmail.com
} 
Revista Tecné, Episteme y Didaxis: TED. Año 2014, Número Extraordinario. ISSN Impreso: 0121-3814, ISSN web: 2323-0126

Memorias, Sexto Congreso Internacional sobre Formación de Profesores de Ciencias. 08 al 10 de octubre de 2014, Bogotá

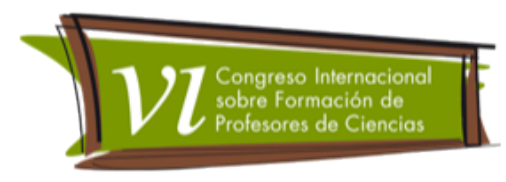

procuramos analisar as contribuições e as implicações dos resultados das pesquisas mapeadas para a formação de professores. Assim, procuramos responder o seguinte problema: Qual a contribuição das pesquisas sobre o ensino da teoria da relatividade especial e geral para mudanças e inovações da prática didático-pedagógica de professores de física?

\section{Marco Teórico}

Nas últimas décadas, a área de Pesquisa em Ensino de Física produziu um significativo conjunto de estudos dedicados na análise da inserção de tópicos de Física Moderna e Contemporânea em aulas de física, sejam elas do Ensino Médio ou de cursos de graduação. Especialmente, no Brasil, esse fato pode ser comprovado pela leitura de revisões de literatura realizadas com foco nesta temática.

Ao consultarmos bibliografias que versam sobre as pesquisas do tipo "Estado da Arte", encontramos posições como as de Romanowski e Ens (2006). Para elas, estados da arte podem significar uma contribuição importante na constituição do campo teórico de uma área de conhecimento, pois procuram identificar os aportes significativos da construção da teoria e prática pedagógica, apontar as restrições sobre o campo em que se move a pesquisa, as suas lacunas de disseminação, identificar experiências inovadoras investigadas que apontem alternativas de solução para os problemas da prática e reconhecer as contribuições da pesquisa na constituição de propostas na área focalizada (pág. 39).

As autoras esclarecem que há uma diferenciação entre "Estado da Arte" e "Estado do Conhecimento". Para elas, em uma pesquisa do tipo "Estado da Arte" não basta apenas estudar os resumos de dissertações e teses, são necessários estudos das produções em congressos e em periódicos. Já o estudo que aborda apenas um setor das publicações sobre o tema estudado é denominado de "Estado do Conhecimento".

Podemos dizer que as pesquisas do tipo "Estado da Arte" e "Estado do Conhecimento" buscam organizar o conhecimento acumulado em uma área do saber. De maneira atualizada; procuram sistematizar "o que sabemos" e "o que se fez" em um dado período e em uma determinada área/linha de investigação. É no conjunto de estudos do tipo "Estado do Conhecimento" que se insere o presente trabalho. 
Revista Tecné, Episteme y Didaxis: TED. Año 2014, Número Extraordinario. ISSN Impreso: 0121-3814, ISSN web: 2323-0126

Memorias, Sexto Congreso Internacional sobre Formación de Profesores de Ciencias. 08 al 10 de octubre de 2014, Bogotá

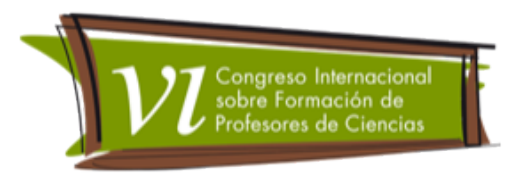

\section{Metodologia}

Para conhecermos as contribuições das pesquisas sobre o Ensino da TREG para a prática pedagógica de professores, traçamos um panorama do que se tem pesquisado sobre o ensino e aprendizagem desta teoria a partir do mapeamento dos trabalhos publicados nas atas de três congressos científicos, realizados no âmbito brasileiro, são eles: Encontro Nacional de Educação em Ciências - ENPEC (I até a IX edição), Encontro de Pesquisa em Ensino de Física - EPEF (I até a XIV edição) e o Simpósio Nacional de Ensino de Física - SNEF (I até a XX edição).

Após a identificação das produções, realizamos a leitura cuidadosa de cada uma das produções, na integra. Na sequência, analisamos as produções e tabulamos os dados encontrados com a elaboração de registros em quadros e tabelas. As produções foram analisadas por meio das seguintes categorias: frequência de produções, abordagens teórico-metodológicas, focos dominantes, lacunas existentes, avaliação da aprendizagem, principais resultados e conclusões.

Ao final, descrevemos os resultados a que chegamos, sistematizando as contribuições das pesquisas identificadas para mudanças e inovações da prática pedagógica.

\section{Resultados}

Mapeamos 44 estudos, sendo 8 deles publicados no ENPEC, 16 no EPEF e 20 no SNEF. Obtivemos um total de 20 trabalhos voltados para o ensino da TREG no Ensino Médio (2 no ENPEC, 7 no EPEF e 11 no SNEF), e 15 para o Ensino Superior (5 no ENPEC, 6 no EPEF e 4 no SNEF). Os demais trabalhos não são direcionados a um nível específico de ensino, sendo por vezes reflexões teóricas sobre 0 desenvolvimento da TREG ou abordam outros aspectos. Dos estudos identificados, 43 centram-se no ensino de Relatividade Restrita e apenas 1 na Relatividade Geral.

No que tange às abordagens teóricas, verificamos uma vasta gama de referenciais utilizados, tanto para o desenvolvimento da pesquisa, como para a análise dos dados ou ainda para avaliar a formação de conceitos pelos alunos. Dentre os referenciais utilizados estão os seguintes: Análise de Discurso na perspectiva de Michel Pêcheux; Semiótica de Algirdas Julien Greimas.; Perfis Conceituais de Eduardo F. Mortimer; Transposição didática de Chevallard; Teoria Construtivista de Jean Piaget; Teoria Sócio-interacionista de Lev Vygotsky e; Aprendizagem Significativa de David Ausubel. 
Revista Tecné, Episteme y Didaxis: TED. Año 2014, Número Extraordinario. ISSN Impreso: 0121-3814, ISSN web: 2323-0126

Memorias, Sexto Congreso Internacional sobre Formación de Profesores de Ciencias. 08 al 10 de octubre de 2014, Bogotá

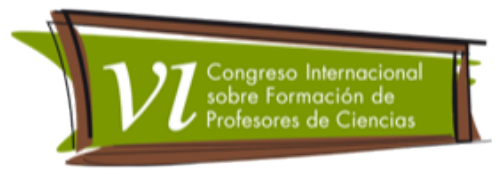

Os referenciais teóricos adotados estão fortemente ligados ao referencial utilizado no grupo de pesquisa no qual o estudo foi realizado e, ainda, pelo fato de alguns estudos avaliarem a aprendizagem dos alunos, o que os obriga a usarem referenciais cognitivos, muitas vezes oriundos e próprios da Psicologia da Educação.

Por meio da identificação quantitativa dos estudos conseguimos conhecer os principais focos dominantes das pesquisas, são eles: a) Formação de conceitos/Levantamento de concepções dos Alunos; b) Formação de Professores; c) História/Filosofia da Ciência; d) Produção de material didático; e) Implementação de proposta didática; f) Análise dos conteúdos em livros.

Os conjuntos mais significativos de produções são aqueles referentes a formação de conceitos (13), análise de livros didáticos (10) e implementações de propostas didáticas (7).

A avaliação da aprendizagem dos alunos e, consequentemente, as propostas de ensino foram avaliadas, na maioria dos casos, por meio de pré e pós-testes. Além destes, foram utilizados mapas conceituais, questionários, entrevistas, provas e demais produções textuais dos alunos.

A análise das produções permitiu verificarmos os principais resultados que as pesquisas obtiveram, entre vários destacamos: a) os alunos demostraram não possuir conhecimento das crises ocorridas e que levaram ao desenvolvimento da Teoria da Relatividade e não diferem a Física Clássica da Física Moderna; b) os alunos articularam a teoria estudada com alguns acontecimentos históricos, tais com a Segunda Guerra Mundial; c) os alunos com interesse na área de exatas alegaram descontentamento com o modelo de aula diferenciado, já os alunos com aptidão para a área de humanas se mostraram favoráveis pela abordagem histórica; d) os alunos despertaram interesse por histórias que relatam a evolução da ciência, desenvolvendo reflexões e discussões a respeito do modo como os cientistas trabalham e comentando positivamente $\mathrm{o}$ uso de textos mesclando Física, Literatura, História e Filosofia; e) os professores se mostraram favoráveis a inserção da teoria da relatividade no Ensino Médio, muitos deles não abordam este tópico em suas aulas; f) umas da dificuldades da inserção de tópicos no Ensino Médio é o despreparo e a resistência que muitos professores possuem; g) o uso de simulações computacionais mostrou-se benéfico; h) os estudantes manifestaram resistência à aceitação dos postulados, elucidando suas concepções clássicas e evidenciando processo de conflito; i) a abordagem histórico-filosófica tornou a Física mais interessante, mostrando-se uma 
Revista Tecné, Episteme y Didaxis: TED. Año 2014, Número Extraordinario. ISSN Impreso: 0121-3814, ISSN web: 2323-0126

Memorias, Sexto Congreso Internacional sobre Formación de Profesores de Ciencias. 08 al 10 de octubre de 2014, Bogotá

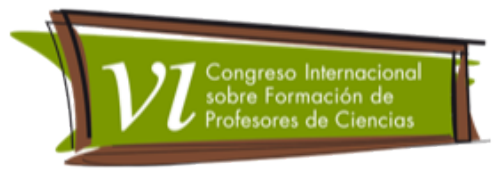

abordagem positiva e adequada para envolver o aluno em discussões; j) os livros didáticos do Ensino Médio mostram-se como simplificações do universitários, de forma que o aparato matemático rebuscado dá lugar a equações e funções mais simples; k) a teoria da relatividade especial é inicialmente não plausível, devido principalmente à natureza contra intuitiva de seus postulados. O conteúdo é sofisticado o que dificulta a utilização de certas estratégias, como as baseadas em anomalias ou conflitos com as concepções existentes. A maioria dos alunos acaba convivendo com esse desajuste entre os resultados da teoria e suas preconcepções. A teoria é muitas vezes assimilada "à força"; l) as imagens de trens, réguas, relógios, gêmeos e plataformas desempenharam um papel fundamental na produção de sentidos da Teoria da Relatividade.

Por vezes, é possível identificar nas investigações mapeadas um conjunto de recomendações, tanto no que diz respeito ao currículo quanto para a prática pedagógica dos professores, entre as quais destacamos: a) o currículo escolar deve ser reformulado e os livros didáticos devem inserir aspectos da relatividade não apenas nas páginas finais; b) reestruturação geral dos conteúdos de Física Moderna, bem como da própria Física Clássica, uma vez que é necessário fornecer ao aluno uma noção de Eletromagnetismo, ainda no primeiro ano, para que eles possam assimilar melhor os conteúdos de relatividade; c) cuidado deve ser dado ao aparato matemático rebuscado dos livros do ensino médio; d) os professores devem dar ênfase para atividades que explorem o trabalho de Einstein e a Bomba atômica. Ainda, eles devem explorar o uso de textos de divulgação científica; e) dinâmicas em grupo podem auxiliar na aproximação dos conceitos científicos; f) há a necessidade de uma mudança curricular também nos cursos de licenciatura; g) recomenda-se dar ênfase na abordagem histórico-filosófica e na abordagem que considera as relações entre Ciência, Tecnologia e Sociedade, por meio da discussão da equação de massa-energia no desenvolvimento da bomba atômica; h) sugere-se a utilização de aparatos experimentais no Ensino Médio pelos futuros professores.

\section{Conclusões}

Neste trabalho apresentamos parte dos resultados obtidos em uma pesquisa mais ampla, do tipo "Estado da Arte", que objetiva descrever o panorama das investigações sobre o ensino da TREG.

O fato de termos identificado apenas um trabalho sobre o ensino da Relatividade Geral, indica-nos um desinteresse dos pesquisadores em relação a este tópico ou 
Revista Tecné, Episteme y Didaxis: TED. Año 2014, Número Extraordinario. ISSN Impreso: 0121-3814, ISSN web: 2323-0126

Memorias, Sexto Congreso Internacional sobre Formación de Profesores de Ciencias. 08 al 10 de octubre de 2014, Bogotá

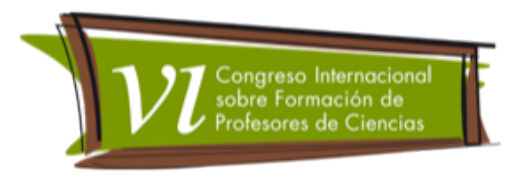

a dificuldade de se elaborar propostas para o seu ensino e, portanto, a necessidade de nos empenharmos na produção e implementação de alternativas para o seu ensino nos diversos níveis escolares.

Identificamos uma grande quantidade de produções, com foco na análise de conteúdos em livros, destinadas ao Ensino Médio, bem como propostas de inserção da TREG neste nível de ensino, permitindo-nos inferir que, a procura por alternativas, para que o ensino da TREG seja realmente efetivo e condizente com a realidade das escolas, se faz necessária e o aumento de investigações no ambiente escolar parece ser o caminho mais apropriado. Aliado a este trajeto, há uma necessidade de investirmos esforços na formação inicial dos professores, para que eles sintam-se seguros para abordar a TREG, quando estiverem em atividade docente. Além disso, deveria haver uma ansiedade por parte dos autores e orientadores em fazer os resultados de suas pesquisas chegarem à sala de aula, colaborando para a melhoria do Ensino de Física nas escolas.

Observamos uma multiplicidade de referenciais teórico-metodológicos. A "Análise de Discurso" de Michel Pêcheux, em foi o principal referencial adotado, seguido por referencias da "Aprendizagem significativa" de David Ausubel.

Pesquisas futuras poderiam se dedicar ao ensino da TREG em outros níveis de ensino como, por exemplo, no ensino superior, investigando como se realiza o ensino deste tópico em cursos de graduação, seja na Licenciatura ou no Bacharelado, com o objetivo de propor mudanças nas práticas dos professores de física deste nível. Argumentamos em favor de futuros trabalhos que tenham como foco as concepções de professores sobre o ensino da TREG e as dificuldades que encontram para efetivá-lo.

\section{Referências Bibliográficas}

Romanowski, J. P.; ENS, R. T. As pesquisas denominadas do tipo "estado da arte" em educação. Diálogo Educacional, v. 6, n. 19, págs. 37-50, setembro/dezembro 2006. 